http://jmscr.igmpublication.org/home/ ISSN (e)-2347-176x ISSN (p) 2455-0450

crossref DOI: https://dx.doi.org/10.18535/jmscr/v7i12.79

Journal Of Medical Science And Clinical Research

\title{
Post Traumatic Pseudo-aneurysm of Deep Palmar Arch: A Case Report
}

\author{
Authors \\ Dr Aditya Vora ${ }^{1}$, Dr Amarnath Munoli ${ }^{2}$, Dr Jinisha Bhanushali ${ }^{3}$ \\ ${ }^{1}$ Superspeciality Medical Officer in Department of Plastic and Reconstructive Surgery LTMGH, Sion, \\ Mumbai \\ ${ }^{2}$ Associate Professor, Department of Plastic and Reconstructive Surgery LTMGH, Sion, Mumbai \\ ${ }^{3}$ Final year Resident, in Department of Plastic and Reconstructive Surgery LTMGH, Sion, Mumbai \\ *Corresponding Author \\ Dr Amarnath Munoli
}

$4^{\text {th }}$ Floor Room Number 450 College Building Department of Plastic Surgery Sion Hospital Mumbai 400022

\begin{abstract}
Introduction: Pseudoaneurysm of the deep palmar archis a rare entity, with only few cases described in the literature. A high index of suspicion is necessary for the diagnosis and treatment. Below we present a case of a pseudoaneurysm of the deep palmar arch in an18-year-oldman following a sharp cut injury over the dorsum which was treated surgically in our department.

Case Report: An18-year-old man, right-handed, reported to our department with a swelling over the dorsum of left hand, following accidental trauma to the dorsum with a knife that was sutured locally one month ago. Swelling was insidious in onset, gradually progressed to the present size. On clinical examination, a scar visible over the dorsum, non-tender, pulsatile swelling of $3 \mathrm{cms} \times 5 \mathrm{cms} x 4 \mathrm{cms}$ under the scar, overlying skin freely mobile, radial and ulnar pulses were well felt, no signs of distal ischemia in the fingers, no sensory changes present. Plain radiograph of the left hand was normal. MRI revealed a 2.2 $x 4.6 \times 3.2 \mathrm{cms}$ pseudoaneurysm deep to extensor tendons, third and fourth metacarpal bones with branch of radial artery in close proximity. Digital subtraction angiography did not show any blush or filling up of the pseudoaneurysm. On Surgical explorationthe Pseudoaneurysm was found to be thrombosed and excised in toto. The scar healed well and patient had no complications.

Conclusion: Pseudoaneurysm of the palmar arch after local penetrating trauma is an important differential for patients presenting with palmar or dorsal masses. Pseudoaneurysm can be effectively diagnosed and treated surgically with excellent results.
\end{abstract}

Keywords: Pseudoaneurysm, deep palmar arch, Digital subtraction angiography.

\section{Introduction}

The term aneurysm is derived from the Greek word, meaning, "a widening". By current reporting standard, an aneurysm is defined as a permanent localized dilatation of artery having at least $50 \%$ increases in diameter compared with the expected normal diameter ${ }^{1}$. Pseudoaneurysms are distinguished from true aneurysms, which involve the entire arterial wall. False aneurysm, also known as pseudoaneurysm (PA), occurs when a damaging force is applied to the arterial wall, allowing persistent extravasations of blood into the surrounding connective tissues that communicate with the arterial lumen ${ }^{2}$. Currently, surgery or endovascular intervention is the only accepted definitive therapy for these ${ }^{3}$. 


\section{Case Report}

An18-year-old boy, right-handed, reported to our department with a swelling over the dorsum of left hand, following accidental trauma to the dorsum of the hand with a knife that was sutured locally one month ago. The incised wound was approximately $2 \times 1 \mathrm{~cm}$. Post operatively after 2 weeks patient noticed a swelling which gradually progressed and increased to the present size. There was no history of pain, fever or any other surgical procedure done for the same. Patient did not have any history of wound infection or any other complication till the time of suture removal. On clinical examination, a scar visible over the dorsum, non-tender, pulsatile swelling of $3 \mathrm{cms}$ x 5 cms $\mathrm{x} 4 \mathrm{cms}$ under the scar, overlying skin freely mobile, radial and ulnar pulses were well felt, no signs of distalischemia in the fingers, no sensory changes present. There was restriction of flexion of the MCP joints of the index, middle, ring and little fingers. Plain radiograph of the left hand was normal. MRI revealed a $2.2 \times 4.6$ × $3.2 \mathrm{cms}$ pseudoaneurysm deep to extensor tendons, third and fourth metacarpal bones with branch of radial artery in close proximity. DSA did not show any blush or filling up of the pseudoaneurysm. On Surgical exploration the Pseudoaneurysm was found to be thrombosed and excised in toto. The scar healed well and patient had no complications at 6 months follow up. $\mathrm{He}$ is able to completely flex his MCP joints and is able to do all his daily activities.

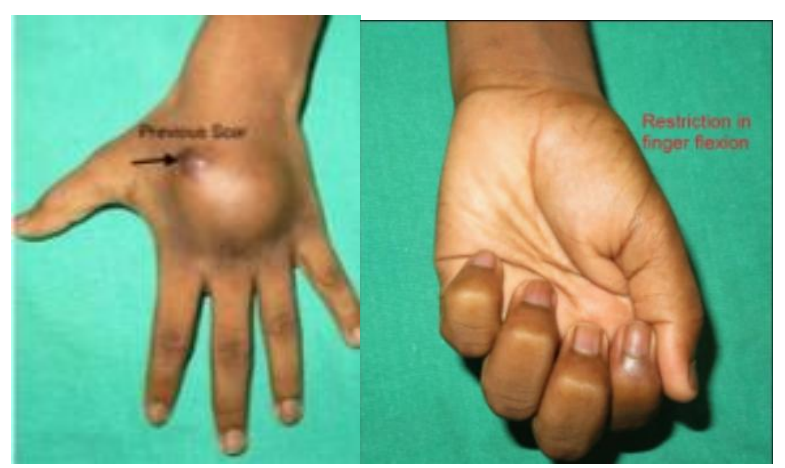

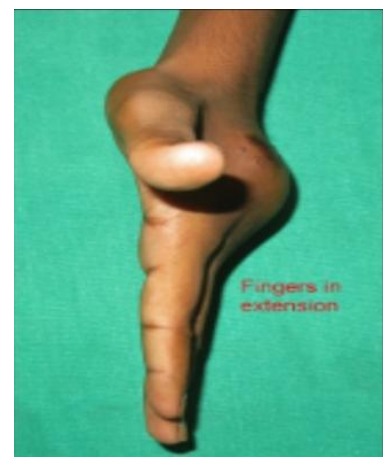

Figure 1 Pre-operative photo of the swelling

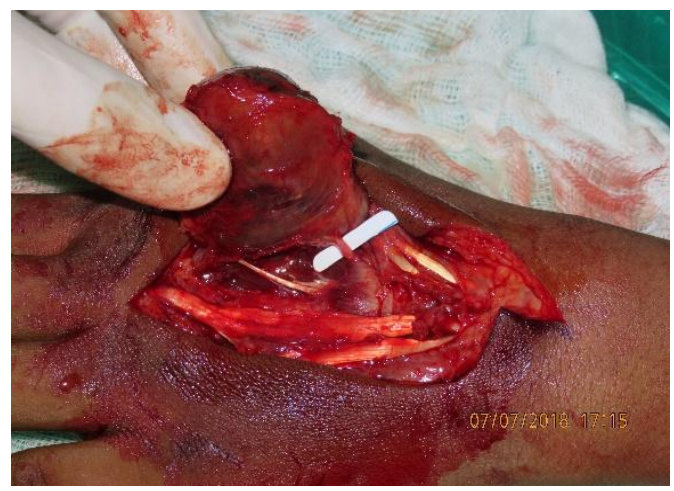

Figure 2 Intra-op picture of the swelling communicating with the vessel

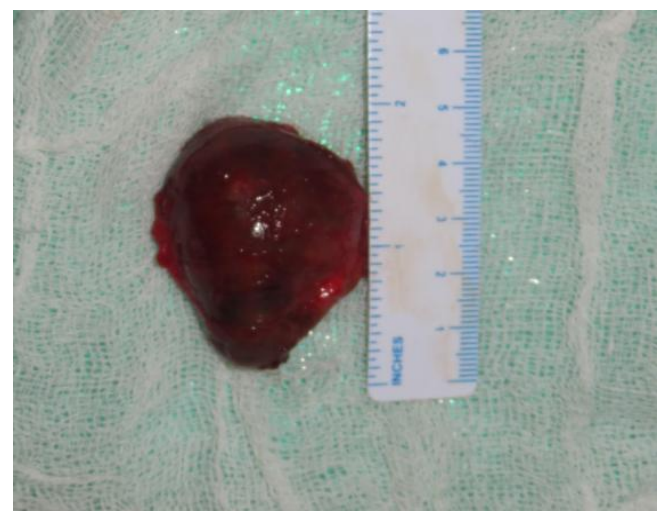

Figure 3 After excision of pseudoaneurysm

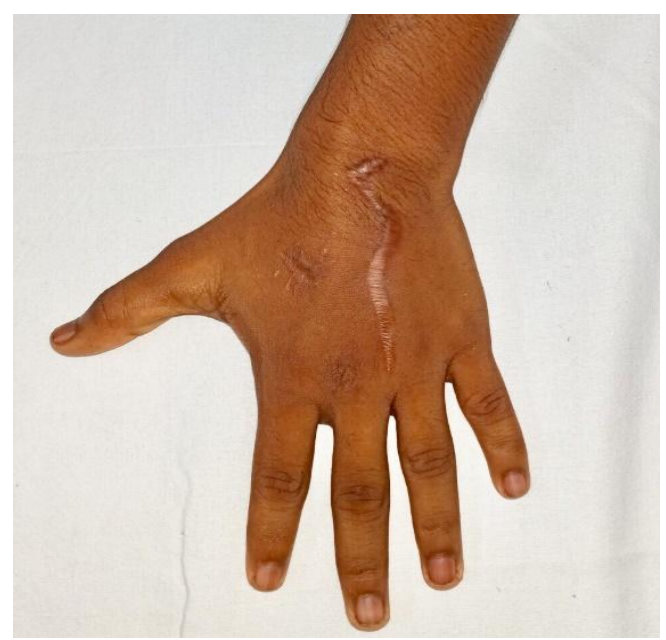



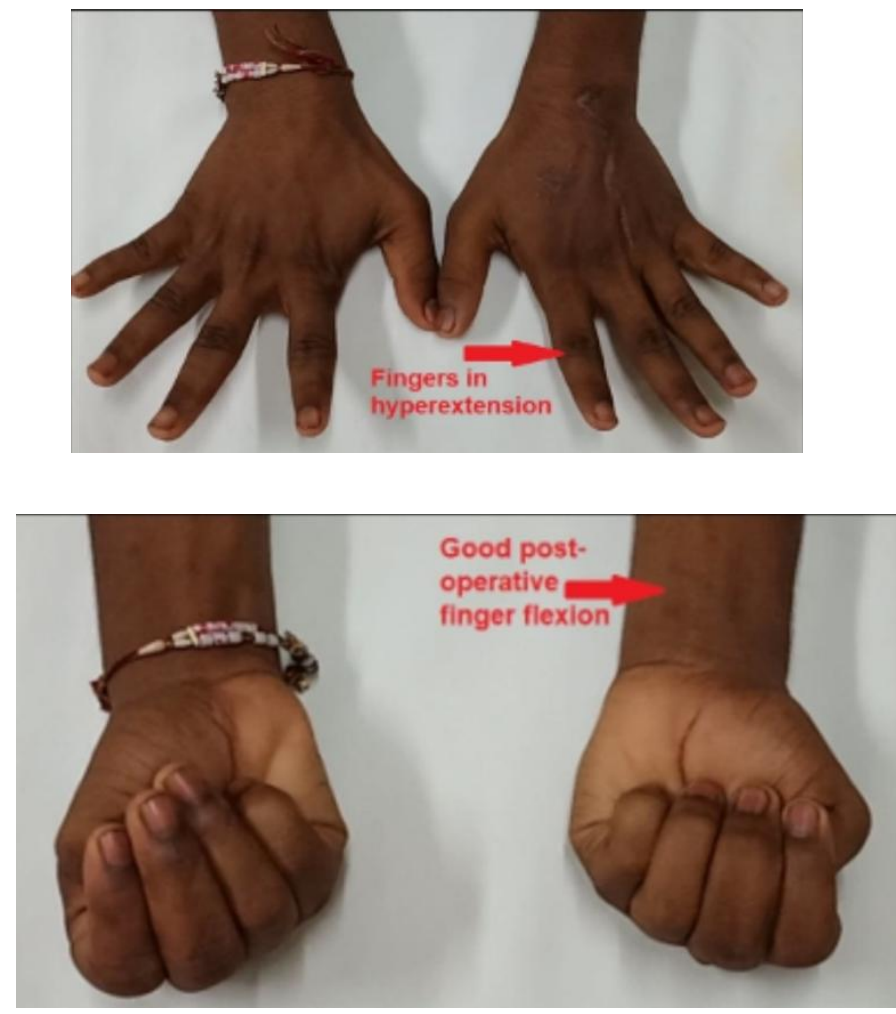

Figure 4 Post operative photos

\section{Discussion}

Arterial aneurysms have been recognized since ancient times. One of the earliest texts known, the Ebers Papyrus (2000 B.C.), contains a description of traumatic aneurysms of the peripheral arteries. Pseudoaneurysms (false aneurysms) are localized arterial disruptions or pulsatile hematoma that communicates with an artery through a disruption in the arterial wall. Pseudoaneurysms are caused by trauma, iatrogenic vascular interventions, anastomotic disruption and in intravenous drug abusers. Pseudoaneurysms are associated with the characteristic findings of a pulsatile mass, a palpable thrill, and an audible to-and-fro murmur. The diagnosis is confirmed by various imaging techniques ${ }^{3,4,5}$. Traumatic pseudoaneurysms have become more commonplace because of increasing civilian violence in society. Pseudoaneurysms occurring as a result of immediate or occult trauma have been reported in virtually every artery. Other false aneurysms of arteries can occur with blunt injury in the form of fracture and dislocation of joints. Their presentation varies with anatomical location. They are also found in intravenous drug abusers ${ }^{6,7,8,9,10,11,12}$.
Pseudoaneurysms of the deep palmar arch are rare entities and only a few cases have been described in the literature. The majority develop secondary to trauma, interventional procedures and infections, and may occur within hours or months. Symptoms may be either due to mass effect, digital ischemia by thromboembolism or arterial occlusion, neurological deficits, venous compression, rupture or abscess formation. Ultrasonography can diagnose a pseudoaneurysm with the classical Ying yang sign and further an MRI and a digital subtraction angiography can be done to note the arterial feeder. Even with multiple treatment modalities like USG guided compression, injection of thrombin or glue into the pseudoaneurysm, surgical resection has been described the best in literature.

\section{Conclusion}

Pseudoaneurysms should always be kept in the differential diagnosis of any swelling especially with a history of trauma. Once diagnosed surgery is a good treatment modality for such lesions.

Conflict of interest: The authors have no conflict of interest to report

Acknowledgement: None

\section{References}

1. Johnston KW, Rutherford RB, Tilson MD, et al. Suggested standards for reporting on arterial aneurysms. J Vasc Surg 1991; 13: 452-58

2. S.P. Lo, C.C. Hsieh, C.Y. Yang, C.J. Lin, C.W. Chang Delayed superficial femoral artery pseudo aneurysm following distal femoral shaft fracture: a case report Kaohsiung J Med Sci, 27 (2011), pp. 242246

3. Cronenwett JL, Krupski WC. OverviewArterial Aneurysms. In: Rutherford RB (ed). Vascular Surgery: 5th ed., Vol. 2, Philadelphia, WB Saunders, 2000, pp. 1241-45 
4. Hiatt JR, Hiatt N: Bloodletting in ancient and modern times. Contemp Surg 1996;48:164-68.

5. Debakey NE: The development of vascular surgery. Am J Surg 1979; 137: 697-738.

6. Holland AJA, Ibach EG. False aneurysm of the inferior gluteal artery following penetrating buttock trauma: Case report and review of the literature. Cardiovasc Surg 1996; 4: 841-43.

7. Anton GE, Hertzer NR, Beven EG, et al. Surgical management of popliteal aneurysms: trends in presentation, treatment, and results from 1952 to 1984 . J Vasc Surg 1986; 3: 125-34

8. Dawson I, Van Bocket JH, Brand R.et al. Popliteal artery aneurysms: Long-term follow-up of aneurysmal disease and results of surgical treatment. J Vasc Surg 1991; 13: 398-407

9. Stein E. Case report 374. Skeletal Radiol 1986; 15: 391-93

10. Gallen J, Wiss DA, Cantelmo N, et al. Traumatic pseudoaneurysm of the axillary artery: Report of three cases and literature review. J Trauma 1984; 24: 350-54.

11. Majeed L. Pulsatile haemarthrosis of the shoulder joint associated with false aneurysm of the axillary artery as a late complication of anterior dislocation of the shoulder. Injury 1985; 16: 566-67

12. Criado E, Marston WA, Ligush J, et al.: Endovascular repair of peripheral aneurysms, pseudoaneurysms and arteriovenous fistulas. Ann Vasc Surg 1997; 11: 256-63. 